\title{
STUDYING THE SIMILARITIES OF DEFORMATION PROPERTIES OF LEATHER MATERIALS IN THE PROCESS OF CREATING A MODEL OF SHOES
}

\author{
MARYNA MYKOLAIVNA LESHCHYSHYN, SVITLANA STEPANIVNA GARKAVENKO, \\ ANTONINA IVANIVNA BABICH \\ Kyiv National University of Technologies and Design, Ukraine, marfiichuk@gmail.com, \\ garkavenko.s@knutd.com.ua,basienka@ukr.net
}

\begin{abstract}
Determination of values and dependencies of deformation and physical and mechanical properties of materials of shoe models and finished products. According to the results of theoretical, analytical and marketing research, a number of experimental tests of materials have been carried out to prove the practical significance of the work, namely tests for: deformation of the vamp part of the product, uniaxial and biaxial stretching, bending, dry and wet friction, adhesion, elongation and tearing. There has been established the nature of the distribution of the total elongations of the samples of the vamps cut from different areas of the leather, as well as the ability of the leather material to be formed when improving the shape of the product or changing the shape of the shoetree. The processes of deformation of the vamp part of shoe blanks, physical and mechanical properties of different groups of modern materials and values analysis of similarity of their deformation properties have been studied. There has been created a working model-transformer for carrying out preliminary measurement of clients' feet at the individual order. The expediency of these works has been proved experimentally. A working version of a model-transformer for foot measurements has been made and as a result of the works approbation, a sample of shoes has been made. The ergonomic properties of the manufactured footwear have been improved due to the use of materials with enhanced physical and mechanical properties. The article investigates the deformation of the most vulnerable vamp part of the men's model of a typical model, as well as the physical and mechanical characteristics of leather materials for manufacturing models and shoes of this type. Providing high quality and comfort of footwear, accuracy of parameters selection of foot measurement, zones of beams and achievement of form stability of footwear with a top from genuine leathers has been predicted.
\end{abstract}

Key words: deformation, model-transformer, footwear.

\section{INTRODUCTION}

Shoe production has always been an attractive business in steady demand. This has traditionally been the work of shoemakers since ancient times, who made products by hand without the use of equipment. The production of fashion industry custom-made shoes is getting more and more popular every year and has its own segment of consumers.

In the current climate, the topical issue is the production of exclusive individual custom-made shoes that emphasize the customer status, his character and preferences.

This paper analyzes modern materials, consumer choice factors influencing the formation of the innovations range in the production of custom-made shoes, stages of improvement of technological units of foot measurement processes, stages of layout and manufacture of shoes, as well as experimental testing of materials to determine values and dependencies of deformation and physical and mechanical properties of materials of the footwear working model and the finished product, improvement of a foot measurement stage and improvement of functional and operational characteristics of a product with use of modern methods and means of production (Izovit and Naumenko, 2015).

https://doi.org/10.24264/icams-2020.I.10 


\section{SETTING OBJECTIVES}

The current task of modern small private shoe companies specializing in the production of custom-made shoes is to study the preparatory and basic processes of shoe production, namely: measuring the feet and modeling the product model, shaping the product while tightening the sock-bundle of shoes on the shoetree, etc. These studies make it possible to investigate and predict providing high quality, comfort and dimensional stability of shoes with uppers of modern classic and non-typical (python, crocodile) natural leather materials both in the design and manufacture and operation of the product, as well as after repairs and renovation or improving the product design.

Creating a comfortable and convenient shape of the product is one of the main stages of shoe production, the quality and careful implementation of which depends not only on the shape stability and comfort of shoes at the stage of operation, but also the product appearance.

At the initial stage of shoe manufacturing in the process of measuring the feet, the main length, latitude and girth parameters of the foot are selected and set. According to this the design is modeled, a model and then the product is made.

Deformation properties of materials are the most important ones, which largely determine the quality of the main technological operations of footwear production, and on which the product comfort and the preservation of its shape during operation depends.

These studies make it possible to assume and predict the possibility of using for the model manufacture as the main material of the upper shoes and a cheaper segment of materials with similar deformation and physical and mechanical properties to ensure high comfort and stability of shoes made of genuine leather materials when wearing the products.

The works of modern scientists in this direction (Kasyan, 2001; Kozar et al., 2013; Danilkovich et al., 2013; Andreeva et al., 2018; Kozar et al., 2013; Mokrousova and Okhmat, 2013; DSTU 4239-2003; EN ISO 20344: 2004; EN ISO 20345: 2004) suggest the successful use of the same basic high-value leather materials for shoe uppers in the design and manufacture of the product without losing the quality and comfort of the latter. Though there are no studies to confirm the hypothesis in using a cheap segment of materials for the manufacture of the layout, the quality and comfort of the finished product will be high. Therefore, this hypothesis must be tested and confirmed experimentally, because the change in the material type and its properties during the layout of the product and its production can significantly affect the comfort of the finished product and its appearance. These processes have been insufficiently studied, which indicates the relevance of this study.

\section{RESEARCH RESULTS}

In the process of researching and studying the customer base of enterprises working on individual orders, it has been found out that the products price is not the predominant indicator of importance for consumers, but the appearance, comfort and quality of materials are predominant. Therefore, the issues of creating comfortable shoes for manufacturing products must be addressed more deeply at the stage of measuring the feet and layout. To study the issues of improving the stages of measurement, layout and manufacturing the products, its reduction without losing quality and comfort. 
Based on the results of theoretical and analytical, marketing and experimental research, a model-transformer of shoes for preliminary foot measurement was designed (Fig. 1, a) and prototypes of the product model (Fig. 1, b) were made, which were also partially subjected to experimental tests. mechanical properties according to certain importance factors.

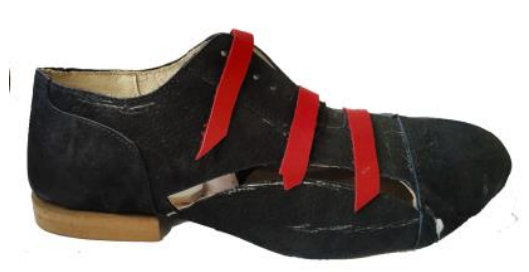

a)

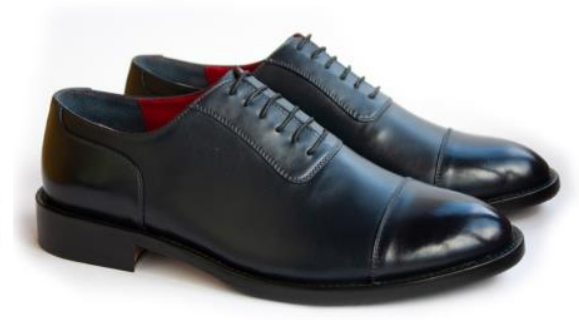

b)

Figure 1. a) Model-transformer shoes for preliminary foot measurement; b) Prototype of a model of manufactured shoes

To study the quality of leather for the shoe upper, 4 samples of genuine leather from different manufacturers have been selected. In general, the organoleptic characteristics of the leather for the shoe uppers are presented in Table 1.

Table 1. Organoleptic characteristics of leather for shoe uppers

\begin{tabular}{ccccc}
\hline Indicator & \multicolumn{4}{c}{ Leather sample } \\
& 1 & 2 & 3 & 4 \\
\hline Name & cattle & crocodile & python & ostrich \\
Code number & 350-P15- 5505 & $650-\mathrm{P}-154352$ & $100-\mathrm{P}-110601$ & 200-P-151215 \\
Colour & bordeaux & blue & white & black \\
Lace & Natural lace & Clearly defined & Natural & Natural clear \\
condition & condition & segments of lace & distinct scales & holes \\
\hline
\end{tabular}

To assess the leather quality according to physical and mechanical properties there has been determined the tensile strength of the material, the relative elongation at a strain of $10 \mathrm{MPa}$, the resistance of the coating to repeated bending, the adhesion of the coating film to wet and dry skin. Samples of the materials described above have been used to evaluate the deformation properties of the materials. According to the methods described in DSTU (DSTU 4239-2003; EN ISO 20344: 2004; EN ISO 20345: 2004) for the relevant tests three samples cut from different leather areas have been taken, they mimicked the vamp ( 3 options). One vamp is cut from the cheprak part in the longitudinal direction, the second - from the cheprak part in the transverse direction, the third is cut from the extreme part of the leather cheprak part in the longitudinal direction. There are totally 15 samples (EN ISO 20345: 2004).

Therefore, the samples selected for research have been evaluated for quality in terms of physical, mechanical and deformation properties. The results of the research are presented in Table. 2 As it can be seen from the data presented in the above tables, the studied leather samples in terms of indicators fully meet the standard requirements for leather for shoe uppers (DSTU 4239-2003; EN ISO 20344: 2004). 
Studying the Similarities of Deformation Properties of Leather Materials in the Process of Creating a Model of Shoes

Table 2. Physico-mechanical tests of skins

\begin{tabular}{lccc}
\hline Sample & $\begin{array}{c}\text { Tensile strength, } \\
\times 9.8 \mathrm{MPa}\end{array}$ & $\begin{array}{c}\text { Relative elongation, with } \\
\text { a load of 9.8 MPa, \% }\end{array}$ & $\begin{array}{c}\text { Elongation at } \\
\text { breaking, \% }\end{array}$ \\
\hline 1 & 1,7 & 54,0 & 80,0 \\
2 & 1,5 & 35,0 & 65,0 \\
3 & 1,6 & 35,0 & 58,0 \\
4 & 1,8 & 24,0 & 59,0 \\
Standard & 1,5 & $20,0-40,0$ & - \\
requirements & & & \\
\hline
\end{tabular}

Therefore, it should be noted that all samples of genuine leather for the shoe uppers according to the indicators of chemical composition, physical and mechanical properties fully meet the requirements of regulatory documents and are safe for human feet.

The second stage of the research was studying the properties of products in order to verify and confirm the similarity of the deformation properties of materials.

For the first type of research, 270-size vamps were selected, designed on a shoetree of style 9112 of medium fullness.

In the process of forming, the vamps on the shoetree are subjected to forced stretching simultaneously in several directions, i.e. there is a multi-axis deformation.

According to the method (Kozar et al., 2013), a grid of lines is applied on the flesh side of the detail imitating the vamp, this grid forms squares of size $20 \times 20 \mathrm{~mm}$. Transverse lines are drawn perpendicular to the inflection line of the vamp and numbered in Arabic numerals, longitudinal lines are numbered in Roman numerals on the inside and outside of the vamp.

In the process of forming, the vamps on the shoetree are subjected to forced stretching simultaneously in several directions, i.e. there is a multi-axis deformation.

Tightening by machine is performed manually. At manual tightening the operation is carried out on nails by means of pincers and a hammer. And it is necessary to consider the fact that the machine movements are identical both on the effort applied to preparation and on frequency of movement reproducibility.

In the process of forming, the vamps on the shoetree are subjected to forced stretching simultaneously in several directions, i.e. there is a multi-axis deformation.

At manual tightening everything is on the contrary. The master cannot reproduce his movements with the same effort and frequency physically, so each movement is different and each tightened area of the workpiece has a different amount of material stretching, but we are interested in this option.

After tightening and performing various groups of forming operations, the samples are kept for some time on the shoetree and then removed. Measurements of material deformation along the total length of lines and sides of squares have been performed during the study 3 times with a caliper under a microscope with an accuracy of $0.1 \mathrm{~mm}$.

The values of measuring the size of each square of the six samples of the first, second and third options after deformation have been averaged and taken into account changes in deviations of $\pm 2.5 \%$ or more from the original size.

The reliability of the experimental research results has been assessed by traditional methods of mathematical statistics. The standard deviation $\sigma_{\mathrm{B}}$, the coefficient of variation $v$ and the parameters reflecting the proximity of the research results is the accuracy of the test $\delta$ were determined (Danilkovich et al., 2013).

The results of tests of experimental leather and samples indicate the ability of the material to forming and repeated deformation (Fig. 2).

https://doi.org/10.24264/icams-2020.I.10 
When forming the workpiece of the shoe upper, the leather structure can change significantly as a result of tensile and flexural deformations: the bundles of fibers are able to navigate under the action of tensile loads and bend elastically.

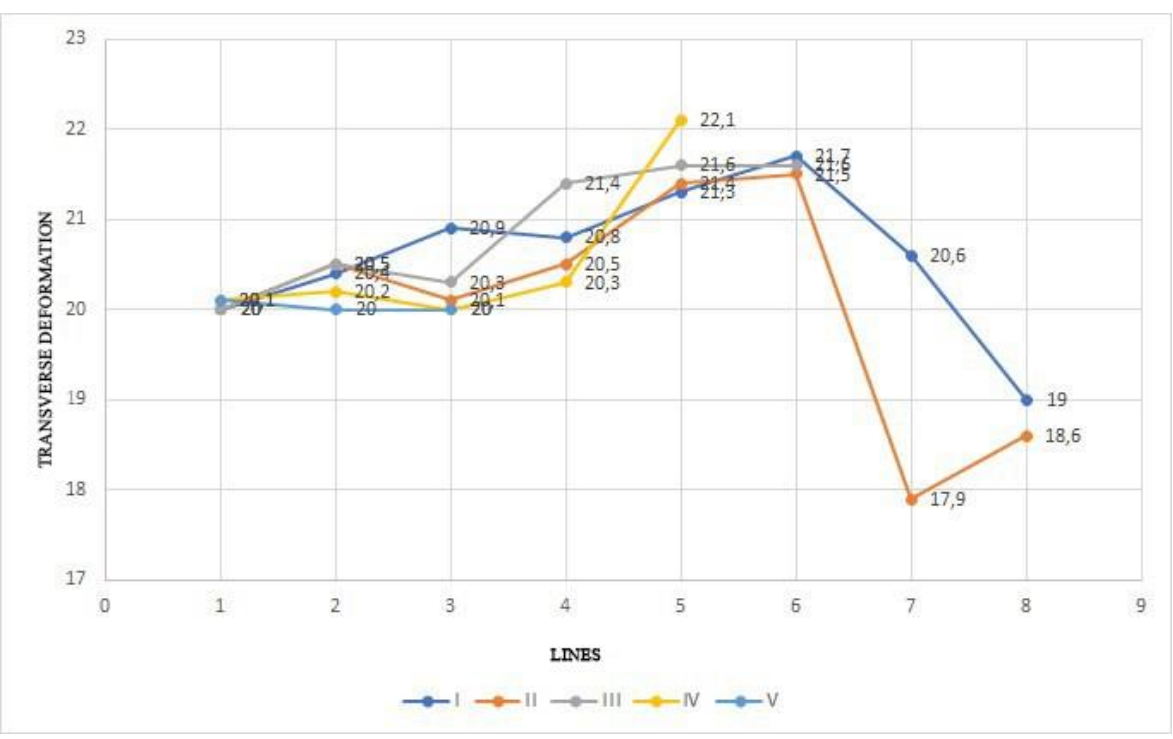

Figure 2. The results of transverse deformation

\section{CONCLUSIONS}

Genuine leather has a wide range of applications. Most of it is aimed at making leather for the shoe uppers`. Therefore, quality control of genuine leather is a very important factor. Since a person spends a long time in shoes, it is important to feel comfortable and convenient. Given the relevance and feasibility of the purpose of this study, to assess the quality, samples of selected leather of exotic animals of foreign production have been chosen.

The processes of deformation of the vamp part of shoetrees, physical and mechanical properties of different groups of modern materials and analysis of the values of similarity of their deformation properties have been investigated.

The working model-transformer for carrying out preliminary foot measurement of customers at the individual order has been created, and as a result of approbation of the works, the sample of footwear has been made.

The expediency of these works has been proved experimentally. The ergonomic properties of the manufactured footwear have been improved due to the use of materials with enhanced physical and mechanical properties.

Providing high quality and comfort of footwear, accuracy of selection of parameters of foot measurement, zones of beams and achievement of form stability of footwear with a top from genuine leather at formation on shoetrees of various styles and forms has been predicted. 
Studying the Similarities of Deformation Properties of Leather Materials in the Process of Creating a Model of Shoes

\section{REFERENCES}

Andreeva, O.A., Hryshchenko, I.M. and Zvarych, I.T. (2018), Features of leather and fur raw materials: Svit uspichy, Ukraine, p. 451.

Danilkovich, A.G., Hryshchenko, I.M. and Lishchuk, V.I. (2013), Innovative technologies for the production of leather and fur materials and products: a monograph, p. 344.

Izovit, T. and Naumenko I. (2015), “Trends in Ukrainian leather production market”, Light industry, № 4. p $2-4$

Kasyan, E.E. (2001), Fundamentals of leather and fur technology: a textbook.

Kozar, O.P., Mokrousova, O.R. and Konoval, V.P. (2013), "Evaluation of relaxation and deformation characteristics of leather for shoe uppers filled with natural minerals", Bulletin of the Kyiv National University of Technologies and Design - №4. - P. 107-115.

Kozar, O.P., Mokrousova, O.R. and Victor, M.T. (2013), "Evaluation of the stability of leather modified with organic mineral compositions", Scientific notes. - Lutsk: - Issue. 41. - P. 135-137.

Mokrousova, O.R. and Okhmat, E.A., (2013), "Formation of operational properties of leather using montmorillonite", Materials IX Int. Scientific-Practical Conference "Leather and fur in the XXI century: technology, quality, ecology, education", Ulan-Ude, Russia, Publishing house VSGUTU, - P. 83-92.

*** (2003), Derzhspozhivstandard of Ukraine (Effective from 01-10-2004), Textile and leather materials and household products. Basic hygienic requirements: DSTU 4239-2003.

*** (2009), Derzhspozhivstandard of Ukraine (Effective from 2012-01-01), Personal protective equipment. Professional shoes. Shoe test methods (EN ISO 20344: 2004 / AC: 2005 / A1: 2007, IDT): DSTU EN ISO 20344: 2009.

*** (2012), Derzhspozhivstandard of Ukraine, Personal protective equipment. Household shoes. Technical conditions (EN ISO 20345: 2004 / AC: 2007 / A1: 2007, IDT): DSTU EN ISO 20345: 2009. 